\title{
Thermal Voltage Converters and Comparator for Very Accurate AC Voltage Measurements
}

\author{
E. S. Williams \\ Institute for Basic Standards, National Bureau of Standards, Washington, D.C. 20234 \\ (July 22, 1971)

\begin{abstract}
A new fourteen-range set of thermal voltage converters and a thermoelement comparator are used to measure ac-dc difference, and a-c voltages relative to external d-c standards, with $20 \mathrm{ppm}$ (partsper-million) accuracy at audio frequencies. The imprecision is less than $2 \mathrm{ppm}$. Corrections relative to the very stable middle ranges can be redetermined for every range by a seven-step intercomparison of certain adjacent ranges.
\end{abstract}

Key words: AC-DC difference; comparator; thermoelement; transfer voltmeter; voltage measurements.

\section{Introduction}

An a-c voltage at audio frequencies is measured most accurately at the present time by using a thermal voltage converter (TVC) to compare it with a stable and accurately measured $\mathrm{d}$-c voltage, which is nominally equal to it. The basic d-c standards are then, in effect, "transferred" to the a-c measurement. The TVC may be simply a thermoelement (TE) in series with an appropriate multiplier resistor. The output emf of the TE is ordinarily monitored with a nul detector and a balancing circuit, which may be a Lindeck potentiometer. A balancing circuit and a null detector are included in most commercial multirange models.

Before the TVC is used for a-c voltage measurements it must be tested for ac-dc difference or frequency influence so that corrections may be applied. The set of TVCs and the new TE comparator described in this paper were developed primarily for making these tests. However they may also be used for a-c voltage measurements as explained in section 9. For ac-dc difference measurements the TE comparator, whose read out instrument may be either a nanovoltmeter or a galvanometer, provides a considerable advantage over other methods in overcoming the difficulties caused by power supply instability and inexact voltage control.

The 14-range set of TVCs (designated No. 7) consists of six resistor units and two TEs, and extends from 1 to $1000 \mathrm{~V}$. The TEs are rated at 2.5 and $5.0 \mathrm{~mA}$, and each one may be attached to any one of the resistors by a coaxial connector (see fig. 1). This permits each resistor o be used for two voltage ranges, as shown in table 1. Certain adjacent ranges of the set can be interompared, and the ac-dc differences of all the ranges can be determined relative to any one range. This set is otherwise similar to an earlier set $[1]^{1}$, which consisted of two $5-\mathrm{mA}$ TEs and 12 series resistors, and covered a range from 0.5 to $500 \mathrm{~V}$. The earlier set, designated No. 1, has been extended to $1000 \mathrm{~V}$ with one additional resistor as part of the present project. It is evaluated in a 14-step intercomparison in which each range is compared, at reduced voltage, with the next lower one.

In a well designed TVC the ac-de difference is not affected by changes in the applied voltage. Therefore, an ac-dc difference determined for the $100-\mathrm{V}$ range at $60 \mathrm{~V}$ can be applied as a correction when this resistor is used at $200 \mathrm{~V}$ to test the nominal $300-\mathrm{V}$ range of the next higher resistor. Experience has shown this stepup procedure to be feasible. However if the higher voltage ranges are not carefully built the ac-dc differences can change due to self-heating effects to be described later.

\section{Design and Construction}

The two TEs are mounted in 2-in brass tubes (see figs. 1 and 2, upper right) with coaxial connectors for attaching to a resistor. The $2.5 \mathrm{~mA}$-TE has a $400 \Omega$ heater and is used alone as the $1-\mathrm{V}$ range. The $5 \mathrm{~mA}-\mathrm{TE}$ has a $125 \Omega$ heater and a $275 \Omega$ resistor is added inside its enclosure to make a $400 \Omega, 2-\mathrm{V}$ range.

The middle ranges (six ranges, 3 to $60 \mathrm{~V}$ ) make use of three resistors $-0.8 \mathrm{k} \Omega, 3.6 \mathrm{k} \Omega$, and $12 \mathrm{k} \Omega$ (see table 1). Each of these is a $2 \mathrm{~W}$ metal-film resistor mounted coaxially in a 3 -in brass cylinder $41 / 2$ in long with coaxial connectors at each end.

\footnotetext{
' Figures in brackets indicate the literature references on page 153.
} 


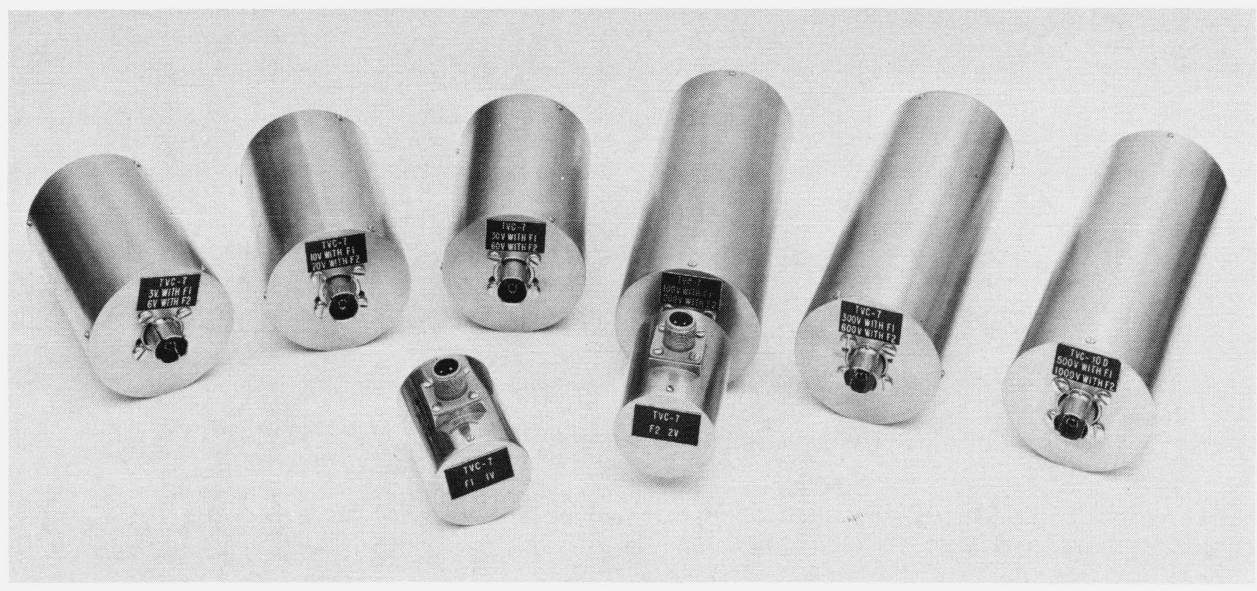

FigURE 1. New set of thermal voltage converters.

The simple symmetrical geometry of these units permits approximate calculations of their reactances [2]. The calculations are inexact because of the necessary assumptions as to end-effects, and they neglect any small residual reactances of the resistors themselves. They do indicate however, that the frequency error of each resistor unit (without the TE) should be less than $1 \mathrm{ppm}$ at $50 \mathrm{kHz}$, even for tubes smaller than 2 in in diameter. (The 3 -in tube was chosen for the higher ranges where more space is necessary and was therefore used for the middle ranges also.)

The higher voltage ranges have larger resistor assemblies to avoid excessive temperature rise. The $100-200 \mathrm{~V}$ unit has a $40 \mathrm{k} \Omega$ spiraled metal-film resistor five inches long. ${ }^{2}$ The 300-600 and 500-1000 V units have resistors of tin oxide deposited on a 0.81 -in glass tube 6 in long. A small voltage coefficient was anticipated in these resistors, but measurements have shown it to be negligible.

${ }^{2}$ This experimental resistor is not ordinarily available commercially. Four $40 \mathrm{k} \Omega$ metal film resistors in series-parallel can also be satisfactory.

TABLE 1. NBS thermal voltage converter set No. 7

Fourteen voltage ranges (column 2) are formed with six series resistors and two TEs (F 1 and $F 2$ ).

\begin{tabular}{|c|c|c|c|}
\hline $\begin{array}{l}\text { Series } \\
\text { resistor }\end{array}$ & $\begin{array}{c}\text { Voltage } \\
\text { range }\end{array}$ & $T E$ & $\begin{array}{c}\text { Total } \\
\text { resistance }\end{array}$ \\
\hline$k \Omega$ & & $m A$ & $k \Omega$ \\
\hline & 1 & 2.5 (F 1) & 0.4 \\
\hline & 2 & $5.0(\mathrm{~F} 2)$ & 0.4 \\
\hline & 3 & 2.5 & 1.2 \\
\hline $0.8 \ldots \ldots \ldots$ & 6 & 5.0 & 1.2 \\
\hline $3.6 \ldots \ldots$ & 10 & 2.5 & 4.0 \\
\hline & $\begin{array}{l}20 \\
30\end{array}$ & $\begin{array}{l}5.0 \\
2.5\end{array}$ & 4.0 \\
\hline $12 \ldots$ & 60 & 5.0 & $\begin{array}{l}12.4 \\
12.4\end{array}$ \\
\hline & 100 & 2.5 & 40.4 \\
\hline $40 \ldots$ & 200 & 5.0 & 40.4 \\
\hline & 300 & 2.5 & 120.4 \\
\hline $120 \ldots \ldots$ & 600 & 5.0 & 120.4 \\
\hline & 500 & 2.5 & 200.4 \\
\hline $200 \ldots \ldots \ldots$ & 1000 & 5.0 & 200.4 \\
\hline
\end{tabular}

Errors in these ranges are caused mainly by capacitance between the resistor assembly and the outer casing, which permits alternating current to bypass the TE to ground. Therefore more a-c than d-c voltage is required for a given TE output. Frequency compensation could be provided by placing relatively small capacitors in parallel with part of the resistance. However, such capacitors probably would not be sufficiently stable over a long period of time and might be affected by temperature changes which occur in the resistor enclosure.

Compensation was therefore provided (as in the earlier set No. 1) with an inner shield which is connected to the input and surrounds the high- or inputend of the resistor (see " $S$ " in fig. 2). The shield is positioned, relative to the resistor, to control the capacitance currents and provide optimum high-frequency
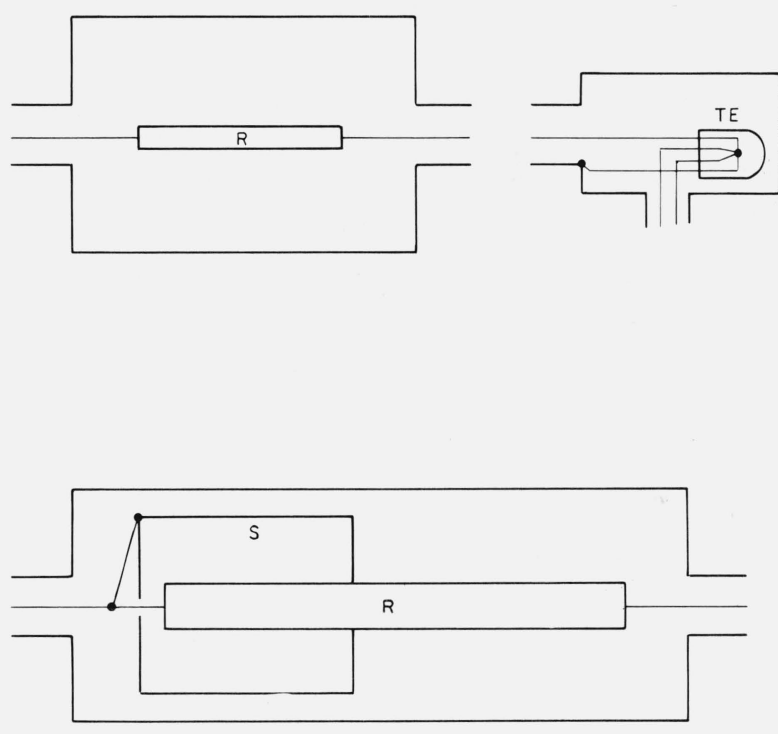

FigURE 2. Essentials of thermal voltage converters. Thermoelement (TE) enclosure, low voltage unit with resistor $(\mathbf{R})$, and high voltage unit $(100$ to $1000 \mathrm{~V})$ with resistor $(\mathrm{R})$ and frequency compensation shield (S). 
compensation; perfect compensation is possible only at one frequency.

\section{1000-V TVC}

As stated earlier the corrections for the high and low voltage ranges are determined relative to the middle range by intercomparison tests. It is necessary therefore that the ac-de difference of all ranges be unaffected by voltage level. The voltage effect is rare in low and middle ranges, but it can be troublesome at higher ranges where the heat generated by the resistor is appreciable. All intercomparison tests were initially made at two voltage levels in order to evaluate this effect-or to prove its absence. If, for example, the nominal $600-\mathrm{V}$ range is compared with the $1000-\mathrm{V}$ range at both 400 and $600 \mathrm{~V}$, and the same results are obtained, it is unlikely that the $600-\mathrm{V}$ range is affected by the voltage increase (the $1000-\mathrm{V}$ range is very probably unaffected at these voltages). However both ranges are in question until we are assured that the $1000-\mathrm{V}$ range is also free of this effect.

The highest range, then presents a special problem. It is more likely to change due to increased voltage (heating) and there is no higher range to compare it with. If it is compared with another $1000-\mathrm{V}$ TVC at two or more voltages and no change is observed it is possible that both have the same voltage effect. However this is unlikely if TVCs are of somewhat different design. If intercomparisons of several units of difference design show no change between rated voltage and a lower voltage we may safely assume this effect is negligible in each one.

Five 1000-V TVCs (table 2) have therefore been built, each with differing components, and a network of intercomparison tests was made as described in the next section. The original set of TVCs [1] was included in these tests.

TABLE 2. Five 1000-V TVCS

\begin{tabular}{|c|c|c|c|c|}
\hline \multirow[t]{2}{*}{ Unit } & \multirow[t]{2}{*}{ Resistance } & \multicolumn{2}{|c|}{ Voltage range with $T E$} & \multirow[t]{2}{*}{ Resistor assembly } \\
\hline & & $F 1$ & $F 2$ & \\
\hline A & $\begin{array}{l}k \Omega \\
400\end{array}$ & 1000 & & $\begin{array}{l}\text { Four } 100 k \Omega \text { wire- } \\
\text { wound resistors in } \\
\text { series, each } 13 / 8 \text { in } \\
\text { long. }\end{array}$ \\
\hline B & 400 & 1000 & & $\begin{array}{l}\text { Four } 100 k \Omega \text { wire- } \\
\text { wound resistors in } \\
\text { series, each } 13 / 8 \text { in } \\
\text { long. }\end{array}$ \\
\hline C & 200 & 500 & 1000 & $\begin{array}{l}\text { Four } 200 \mathrm{k} \Omega \text { metal- } \\
\text { film resistors in } \\
\text { series-parallel, each } \\
2 \text { in long. }\end{array}$ \\
\hline D & 200 & 500 & 1000 & $\begin{array}{l}\text { One } 200 k \Omega \text { tin oxide } \\
\text { resistor } 6 \text { in long. }\end{array}$ \\
\hline $\mathrm{E}$ & 400 & 1000 & & $\begin{array}{l}\text { Four } 400 \mathrm{k} \Omega \text { metal- } \\
\text { film resistors in } \\
\text { series-parallel, each } \\
2 \text { in long. }\end{array}$ \\
\hline
\end{tabular}

The five 1000-V TVCs are designated alphabetically (A through E) ${ }^{3}$ and all except " $\mathrm{A}$ " have the inner shield, as described below, for frequency compensation. The resistor in unit " $\mathrm{A}$ " is mounted concentrically in a set of six brass rings whose potentials are maintained by a capacitance divider. The whole assembly is mounted in a 4-in brass cylinder 7 in long.

Self-heating of a TVC may affect either the frequency compensation or the resistor itself. Apparently the dielectric losses in the insulation between conductors can be affected by heating and change the impedance of the resistor. This change occurred within a few minutes after a voltage increase or decrease in several resistor types, which were therefore discarded.

The frequency compensating shield may be moved, relative to the resistor, by thermal expansion of mounting parts and cause a change in ac-dc difference. This occurred in some of our early units and the change was slow, taking up to an hour. Later shields were therefore mounted very rigidly since a small displacement will have a large effect on the frequency influence.

The shield now in use is in two parts. A brass cylinder, with one end closed, is mounted firmly against the outer end piece (input end) with a polystyrene insulator one-half inch thick (fig. 3). A movable tube fits tightly inside this cylinder and the shield length adjustment is made by pushing this piece forward with a small rod inserted through the end piece and the insulator. The rod is removed after each adjustment.

The shield is most effective at the leading edge where the voltage difference is greatest between the resistor and the shield. Therefore the movable part of the shield is cut at an angle, so that only part of it (see fig. 3) extends outside the fixed cylinder. Thereby the effect of small position changes is reduced. Even so, the compensation is affected by approximately 0.01 percent per millimeter of position change in some typical units.

The shield length adjustment is made in small steps, and tests are made after each adjustment. When optimum compensation is achieved, the unit is opened and the shield parts are locked together with three screws through their overlapping portions.

\section{TE and TVC Tests}

As stated earlier the middle ranges are the most accurate, and they are the base from which higher and lower ranges are tested. However they are no more accurate than the TE used with them. Before being installed in a TVC the TEs are therefore compared with one of a group of carefully selected TE standards which were made according to NBS specifications. This group contains twelve elements made by four manufacturers, and are rated from 5 to $20 \mathrm{~mA}$. [1] They have either Karma or Evanohm ${ }^{4}$ heaters to reduce

\footnotetext{
${ }^{3}$ Unit "D" is assigned to this set (No. 7).

${ }^{4}$ Certain commercial products and instruments are identified in this paper in order to specify adequately the experimental procedure. In no case does such identification imply recommendation or endorsement by the National Bureau of Standards, nor does it imply that the products or equipment identified are necessarily the best available for the purpose.
} 


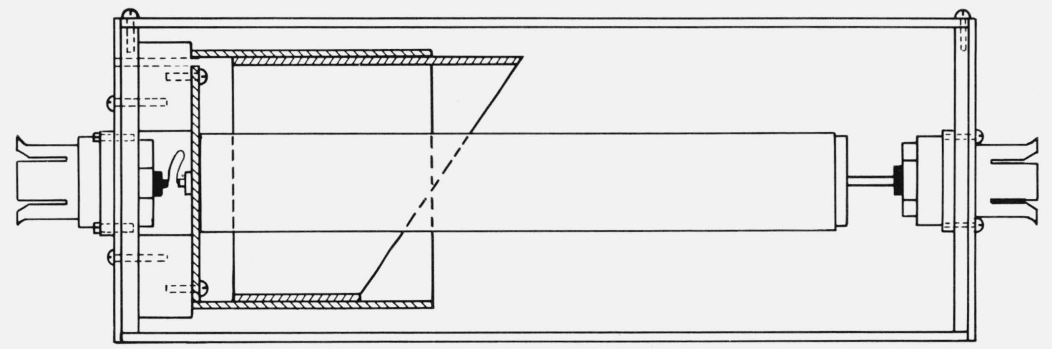

Figure 3. Cross section of high voltage TVC.

Input end is at the left. Fixed and adjustable shield parts are supported by a polystyrene insulator one-half inch thick.

thermoelectric effects in the heaters. They also have small reverse d-c differences (less than $200 \mathrm{ppm}$ ), high bead resistances (over $1000 \mathrm{M} \Omega$ ), and small ac-dc differences. An additional two are multi-junction elements of different design. All of these TEs have been intercompared as current converters with agreement to better than $3 \mathrm{ppm}$. Theoretical calculations, taking into consideration all known sources of error, also indicate that the error should not exceed a few ppm at audio frequencies. Because of this and because of the excellent agreement between these thermoelements of different design and construction, we may safely assume that the average ac-dc difference of the group is 0 to $\pm 2 \mathrm{ppm}$.

The low-frequency performance of a TVC depends on the TE since the reactance of the resistor is entirely negligible even at a few kilohertz. The accuracy of a TE at low frequency is mainly dependent on the length of the heater. A very short heater permits heat to flow more readily to the support stems and cooling to occur between current peaks. However most commercial TEs have errors less than $10 \mathrm{ppm}$ at $20 \mathrm{~Hz}$ and some have errors less than $10 \mathrm{ppm}$ even at $5 \mathrm{~Hz}$.

In testing selected commercial TEs for the TVCs at audio frequencies we often find a small ac-dc difference (up to $4 \mathrm{ppm}$ ) which is independent of frequency but dependent on heater current. It ordinarily decreases at lower heater currents. When these TEs are used in a TVC the ac-dc difference will therefore be slightly voltage dependent. In the step-up test process, where the TVC is alternately used at 50 and 100 percent of rated current, this relatively small thermoelement error is introduced at every step of the process. If the process is a long one, as in the 12-resistor set, there could be a significant accumulation of error. TVCs in the new set are intercompared by testing each resistor once with one TE at reduced current $(60$ or $67 \%$ ), and again with rated current on the other TE. If these TEs differ in ac-dc difference at these currents, there will again be an accumulation of error.

This is one of the advantages of the set with only six resistors. If the $20-\mathrm{V}$ range is the starting point (it is probably the most stable), we have only four steps up to the $1000-\mathrm{V}$ range, and three steps down to the $1-\mathrm{V}$ range. The other advantages are that less time is required for the intercomparisons and there are fewer units to construct.
Intercomparison data for this set of TVCs are listed in table 3 as well as determinations made using TVC set No. 1. (Test methods are discussed in later sections of the paper). The middle ranges differ by $2 \mathrm{ppm}$ or less even though the resistance varies from 1200 to $12000 \Omega$. Since the resistance enters into the theoretical calculation of ac-de difference, this agreement is an additional indication of accuracy.

Step-down tests show that the two lowest voltage ranges usually have a positive correction (i.e., more a-c than d-c voltage is required for a given TE output) of $5 \mathrm{ppm}$ or less at $50 \mathrm{kHz}$. There is no resistor in series with the TE at the $1 \mathrm{~V}$ range, and at the $2-\mathrm{V}$ range the TE is a large part of the total impedance. These ranges are therefore affected more by the small reactance of the TE. The corrections for these ranges are more likely to change if a TE is replaced than for the higher ranges. A step-down test from the middle range is therefore advisable when TE replacements are made.

The five 1000-V TVCs were compared with the $300-$ and $500-\mathrm{V}$ ranges of TVC set No. 1 and the $600-\mathrm{V}$ range of the new set No. 7. The corrections are listed in table 4 for 20 and $50 \mathrm{kHz}$ and all values are averaged.

TABLE 3. $A C-D C$ difference

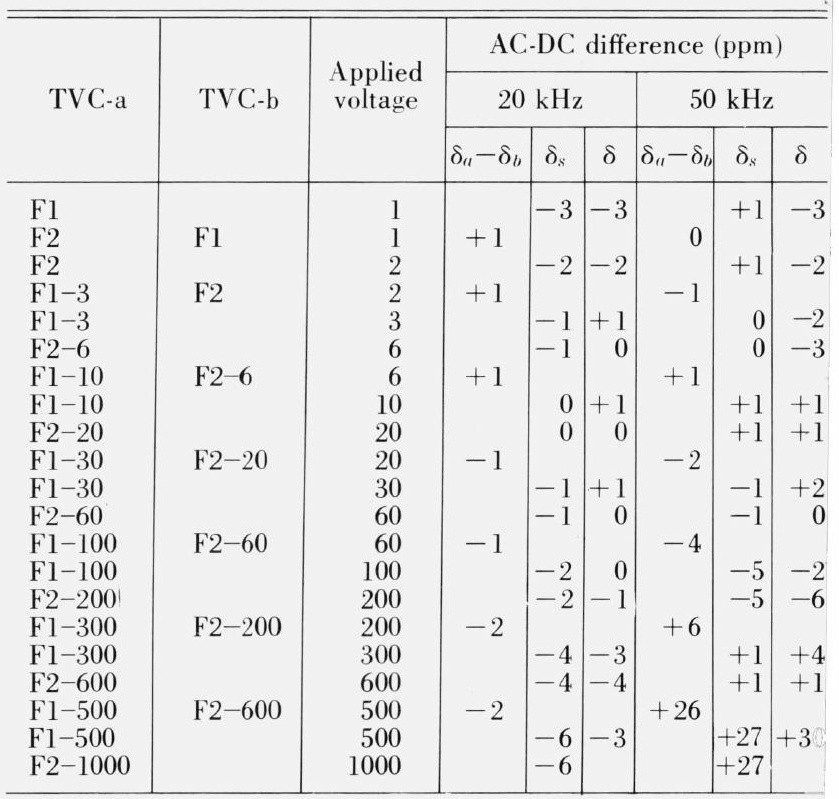


Table 5 lists intercomparison data for the same frequencies for seven pairings of the five 1000-V TVCs. Values for 600 and $1000 \mathrm{~V}$ do not differ significantly and so they are all averaged together.

Corrections $(\delta)$ for each range of the new TVC set are listed as determined in comparison with TVC Set No. 1. Intercomparison data $\left(\delta_{a}-\delta_{b}\right)$ are also listed and a computed correction $\left(\delta_{s}\right)$ based on the intercomparison, starting with the average of the measured ac-dc differences of the $10-$ and $20-\mathrm{V}$ ranges. The TVCs are identified as the combination of a TE (F1 or F2) with the appropriate resistor; i.e., F2-600 forms the $600-\mathrm{V}$ range.

Averages of the corrections for the five $1000-\mathrm{V}$ TVCs listed in table 4 are shown in the circles in figure 4 , and the connecting lines show the intercomparison values from table 5 . The agreement between the various units is illustrated by this figure.

Each of the values listed in tables 4 and 5 is the average of at least four separate determinations. An analysis of the data taken in a series of 26 intercomparison tests (an average of 5 determinations with each one), involving all ranges at two frequencies and usually two voltages, showed an imprecision ( $3 \sigma_{a}$, where $\sigma_{a}$ is the standard deviation of the average of five determinations) of only $1.4 \mathrm{ppm}$.

TABLE 4. Ac-dc difference corrections for five 1000-volt TVC (A-E) The standard instruments are the $300-$ and $500-\mathrm{V}$ units of Set No. 1 and the $600-\mathrm{V}$ range of Set No. 7 .

\begin{tabular}{|c|c|c|c|c|c|c|}
\hline Standard & Volts & A & $\mathrm{B}$ & $\mathrm{C}$ & $\mathrm{D}$ & $\mathrm{E}$ \\
\hline \multicolumn{7}{|c|}{ AC-DC difference at $20 \mathrm{kHz}(\mathrm{ppm})$} \\
\hline $\begin{array}{l}500-1 \\
300-1 \\
600-7 \\
\\
\text { Ave. }\end{array}$ & $\begin{array}{l}500 \\
300 \\
600\end{array}$ & $\begin{array}{l}-3 \\
-8 \\
-6\end{array}$ & $\begin{array}{l}-20 \\
-22 \\
-21\end{array}$ & $\begin{array}{l}-9 \\
-9\end{array}$ & $\begin{array}{l}-4 \\
-4 \\
-2 \\
-3 \\
-3\end{array}$ & $\begin{array}{c}-12 \\
-10 \\
-12,-10 \\
-10 \\
-11\end{array}$ \\
\hline \multicolumn{7}{|c|}{ AC-DC difference at $50 \mathrm{kHz}(\mathrm{ppm})$} \\
\hline $\begin{array}{l}500-1 \\
300-1 \\
600-7 \\
\\
\text { Ave. }\end{array}$ & $\begin{array}{l}500 \\
300 \\
600\end{array}$ & $\begin{array}{l}+21 \\
+30 \\
+23 \\
+25\end{array}$ & $\begin{array}{l}-6 \\
-9 \\
-7\end{array}$ & +11 & $\begin{array}{l}+30 \\
+30 \\
+30 \\
+32 \\
+30\end{array}$ & $\begin{array}{l}-3 \\
-4 \\
-6 \\
-6 \\
-5\end{array}$ \\
\hline
\end{tabular}

TABLE 5. Relative ac-dc differences for seven pairings of members of the five 1000-V TVCs

\begin{tabular}{|c|c|c|c|c|c|c|c|}
\hline Volts & $\delta_{\mathrm{A}}-\delta_{\mathrm{B}}$ & $\delta_{\mathrm{B}}-\delta_{\mathrm{C}}$ & $\delta_{\mathrm{C}}-\delta_{\mathrm{D}}$ & $\delta_{\mathrm{D}}-\delta_{\mathrm{E}}$ & $\delta_{\mathrm{E}}-\delta_{\mathrm{A}}$ & $\delta_{\mathrm{A}}-\delta_{\mathrm{C}}$ & $\delta_{\mathrm{A}}-\delta_{\mathrm{D}}$ \\
\hline \multicolumn{8}{|c|}{ AC-DC difference at $20 \mathrm{kHz}(\mathrm{ppm})$} \\
\hline $\begin{array}{l}600 \\
1000 \\
600 \\
1000 \\
\text { Ave. }\end{array}$ & $\begin{array}{l}-11 \\
-17 \\
-16 \\
-17 \\
-15\end{array}$ & $\begin{array}{l}+14 \\
+13 \\
+17 \\
+15\end{array}$ & $\begin{array}{r}+2 \\
0\end{array}$ & $\begin{array}{r}-7 \\
-6 \\
-10 \\
-7\end{array}$ & $\begin{array}{r}+7 \\
0\end{array}$ & $\begin{array}{l}+3 \\
+9\end{array}$ & $\begin{array}{r}0 \\
+5 \\
-2 \\
+5 \\
+2\end{array}$ \\
\hline \multicolumn{8}{|c|}{ AC-DC difference at $50 \mathrm{kHz}(\mathrm{ppm})$} \\
\hline $\begin{array}{l}600 \\
1000 \\
600 \\
1000 \\
\text { Ave. }\end{array}$ & $\begin{array}{l}-20 \\
-22 \\
-25 \\
-24 \\
-23\end{array}$ & $\begin{array}{r}+14 \\
+6\end{array}$ & $\begin{array}{r}+10 \\
+2\end{array}$ & $\begin{array}{l}-33 \\
-33 \\
-37 \\
-34\end{array}$ & $\begin{array}{l}+28 \\
+35 \\
+32\end{array}$ & $\begin{array}{l}-15 \\
-14 \\
-15 \\
-15\end{array}$ & $\begin{array}{l}+3 \\
+4 \\
+2 \\
+1 \\
+2\end{array}$ \\
\hline
\end{tabular}

\section{Thermal Compensation}

The coaxial connector between the TE and the series resistor provides a low-reactance connection for minimum frequency error. Tests and calculations show the error is less than $1 \mathrm{ppm}$ at $50 \mathrm{kHz}$. However, it also permits heat to flow freely from the resistor, which dissipates up to five watts on the $1000-\mathrm{V}$ range, to the TE which has a temperature coefficient of emf of approximately 0.2 percent $/{ }^{\circ} \mathrm{C}$ (at constant input current).

Heat conduction through the center conductor of this connector was reduced, at $300 \mathrm{~V}$ and higher, by replacing the two polystyrene insulators in the coaxial connectors (one in the resistor output and one in the TE input) with two made of boron nitride. This material is a good electrical insulator and yet it conducts heat well enough to provide an effective heat sink for this conductor. It is used in both ends of the high voltage resistors to improve the heat flow from the resistor to the relatively heavy brass casing. This also helps to reduce the temperature rise in the resistor.

Heat flow through the outer part of these connectors will gradually raise the temperature of the TE casing, and this also causes a heating drift. The increase in temperature of the TE bulb is slowed by mounting it in a short section of brass tubing to increase the thermal mass and this tube is thermally insulated from the TE casing. Thermal compensation is also added by attaching a $10-\Omega$ thermistor to the tube containing the TE and connecting it in series with the TE output. A resistor appropriately chosen to complete the compensation circuit (see Fig. 7 and appendix I) will draw current through the thermistor sufficient to compensate for the temperature increase.

This resistor value may be computed for TEs with average temperature coefficients as in appendix $I$. However, temperature coefficients differ considerably and, for best results, it is usually necessary to match the resistor to the $\mathrm{TE}$ and thermistor combination. A suitable value can be found by substituting a variable resistor outside the TE casing and adjusting it for minimum warmup drift on a $1000-\mathrm{V}$ range. However, if the TVC is to be used with a TE comparator similar to the one to be described, it will frequently be connected
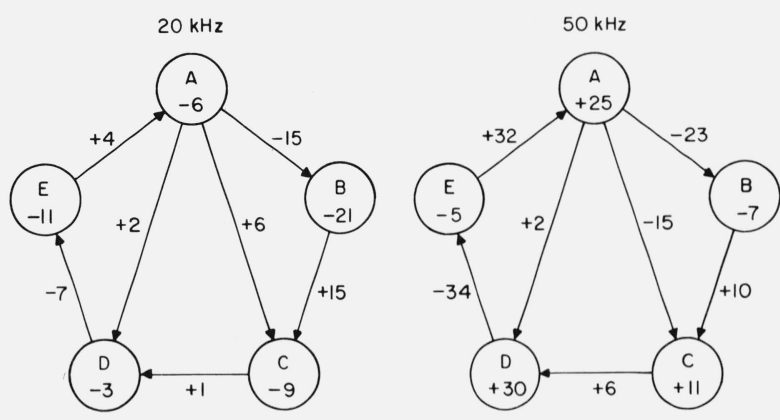

FigURE 4. Intercomparisons of 1000-volt TVCs.

Ac-dc difference corrections (ppm) from table 4 for five 1000-V TVCs are shown in the circles and the relative differences from table 5 are shown on the interconnecting lines. The algebraic difference between any pair should be equal to the figure on the connecting line within experimental error. 
across a $1000-\Omega$ divider, and this will affect the compensation by about 20 percent. A value about 10 percent higher than the one chosen experimentally should provide a satisfactory compromise and reduce the drift by a factor of five or more. With the compensation and the large thermal time constant of the TE in its casing, the drift can be reduced to less than $5 \mathrm{ppm} /$ minute under typical laboratory condition. The error from this is almost completely eliminated by taking a sequence of readings with a-c, $d-c$, reversed d-c, and a-c voltage applied, as described in the next section.

\section{TVC Test Methods}

A brief review of other comparison methods may be useful before describing the TE comparator. Figure 5 shows two TVCs connected in parallel. The separate balancing circuits (or Lindeck Potentiometers) (B) and null detectors (D) may or may not be built in. Stable a-c and d-c voltage supplies are connected to the two TVCs by the ac-dc switch. The switching arrangement shown is typical and convenient, although others, such as reversing the d-c supply by a separate switch, are satisfactory. The d-c supply must have an ungrounded output and it should be possible to ground either terminal as the voltage is reversed. The reversed d-c differences of the TVC can rarely, if ever, be neglected in these tests.

For convenience and clarity, we shall call one TVC the "standard" and the other the "test." Normally the one with known ac-dc difference corrections is the standard, and the test TVC is usually treated differently in the test procedures, as explained below.

There are two procedures for this intercomparison. One might be called a null-balancing method. With a-c voltage applied to both TVCs, the balancing circuits of the test and standard instruments are adjusted to null the detectors. The d-c supply is then switched to the TVCs, and the voltage is adjusted to obtain a null balance first on the detector of the test instrument and then on the standard. Each d-c voltage is carefully measured, and the small difference between the two should equal the difference between the a-c voltage and

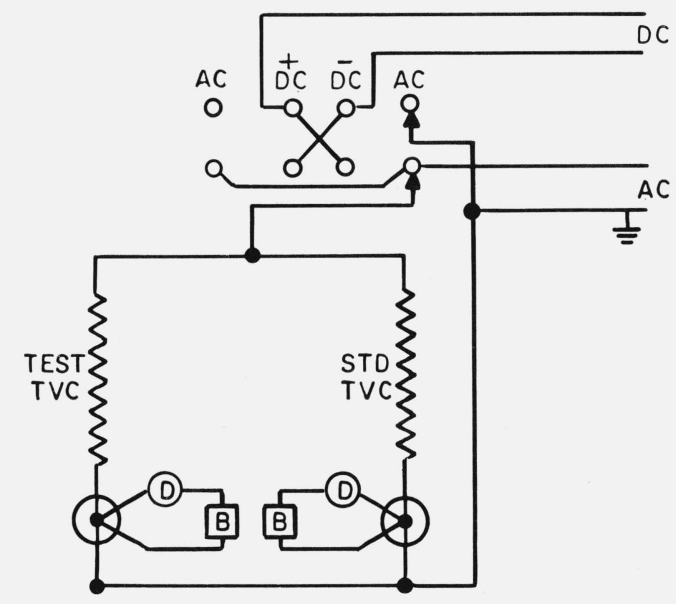

Figure 5. Two-Potentiometer method for TVC comparisnns. one direction of $d-c$ voltage. The measurement is then repeated with reversed $d-c$ voltage, and an average is taken.

This method is tedious and time consuming, an accurate d-c voltage standard is required, and if there is any drift in either instrument output due to warmup or other reasons, as there very often is, the data may lack both accuracy and precision.

A more satisfactory procedure and one that will minimize the effect of drift may be called a deflection method. Both balancing circuits are adjusted to near null, and then a-c and d-c voltages are applied in the succession indicated in figure $5(\mathrm{AC}, \mathrm{DC}+, \mathrm{DC}-, \mathrm{AC})$. For each input the power supply is adjusted to set the test instrument detector to null. The deflection of the standard TVC detector is read for each setting, and the difference between the average reading on a-c voltage and d-c voltage is an indication of relative ac-dc difference. If the readings are made at nearly equal time intervals, and if the drift rate is reasonably constant (even though fairly large), the determinations can be made with satisfactory precision.

If the detector of the standard TVC is a galvanometer the reading may be in divisions or millimeters, but they can be converted to volts or percent ac-dc differences by calibrating the detector scale in one of several ways. A calibration factor can be determined simply and directly by making a small measured change in the $d-c$ input and observing the detector response.

If the detector is a microvoltmeter and if the balancing circuit is a Lindeck potentiometer indicating the millivolt output of the thermoelement, the calibration step can be eliminated. With the four deflection readings on the detector the difference between the average reading on a-c voltage $\left(E_{a}\right)$ and those on d-c voltage $\left(E_{d}\right)$ is computed from the differences of the corresponding readings of the microvoltmeter. The ac-dc difference of the test instrument is

$$
\delta_{t}=\delta_{s}+\frac{E_{s a}-E_{s d}}{n_{s} E_{s d}}
$$

where the subscript $s$ indicates that these values come from the standard instrument, and $\delta_{s}$ is the ac-dc difference correction for the standard. ${ }^{5}$

The factor $n$ relates small changes in thermoelement heater current $(\Delta I)$ (at a fixed frequency) to corresponding changes in output emf $(\Delta E / E=n \Delta I / I$ approximately). For a TVC we may substitute $n \Delta V / V$ for the right hand expression, so that $n=V \Delta E / E \Delta V$. The value of $n$ is 2 if the thermoelement has a square law response, possibly at very low heater currents, but it is usually 1.7 to 1.9 at rated current. Determinations of $n$ should therefore be made in a d-c test at five or more current levels by measuring the values indicated. A plot of $n$ against $E$ can be made so that values corresponding to any emf can be found for substitution in the equation above (see sec. 8).

\footnotetext{
${ }^{5}$ See eq 3 of appendix II. This general formula is applicable here also.
} 


\section{TE Comparator}

There are several variations of basic comparator circuits which are used to minimize the difficulty caused by power supply instability $[1,3]$. They employ a voltage divider circuit to which two emfs are connected. The divider is adjusted to null a detector, and at this point the divider setting corresponds to the ratio of the emfs. If one emf $\left(E_{t}\right)$ is held constant as a-c and then d-c voltage is applied to the TVCs, the other emf $\left(E_{s}\right)$ will change if there is a relative ac-dc difference in the TVCs at the frequency $\left(\delta_{t} \neq \delta_{s}\right)$. The resulting unbalance in the divider will produce a change in the detector deflection proportional to the ac-dc difference. However, small fluctuations in the power supply will produce nearly equal proportional changes in the emfs and therefore the detector will not be affected appreciably. The stabilizing effect depends on how well matched the time constants and response characteristics of the TEs are, but the effect usually affords a significant advantage. Also, the monitored emf need not be held constant so exactly as with a simple balancing circuit.

In the new comparator (fig. 6) the higher of the two emfs is connected across a $1000-\Omega$ Kelvin-Varley divider, and the lower one is connected to the variable tap. The detector is brought to null by adjusting the divider. A Lindeck potentiometer and the same detector (with key $k_{1}$ ) is used to monitor the test TVC output $\left(E_{t}\right)$. The detector is labeled "N" in the diagram because the use of a nanovoltmeter is suggested.

The test procedure is similar to that already mentioned. Preliminary settings of the potentiometer and divider are first made so the readings of the nanovoltmeter will fall near mid-scale. Then with a-c voltage applied, the key $k_{1}$ (labeled "SET" on the instrument, figs. 8 and 9) is depressed and the appro-

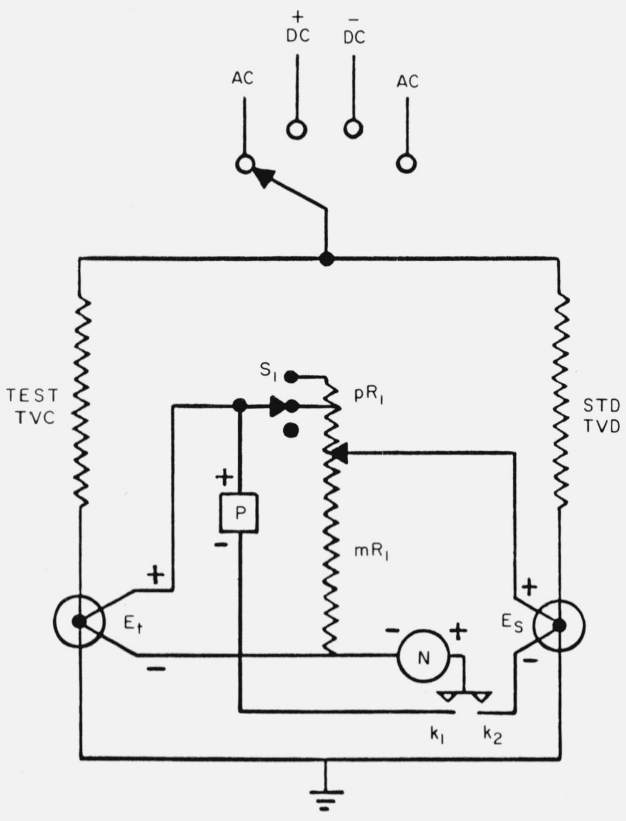

FigURE 6. New TE comparator. priate power supply is adjusted for a null on the detector. Key $\mathrm{k}_{2}$ (READ) is then depressed and the detector indication is read. The two-step procedure is repeated for two directions of $d$-c voltage and for a second a-c input. The average indication in nanovolts ${ }^{6}\left(N_{a}\right)$ for a-c input and the average for d-c input $\left(N_{d}\right)$ is computed and the ac-dc difference of the test instrument is

$$
\delta_{t}=\delta_{s}+\frac{N_{d}-N_{a}}{n_{s} E_{s}} \quad(\text { appendix II eq } 5)
$$

Figure 6 shows the test TVC output $\left(E_{t}\right)$ connected to the high emf terminal ( $\mathbf{E}_{H}$ in fig. 8). If $E_{t}$ is smaller than $E_{s}$ it will be necessary to interchange them, but this is a minor inconvenience. If $E_{t}$ is connected to the $E_{1}$, terminal the potentiometer is switched to that input with switch $\mathrm{S}_{2}$ (fig. 8) and $E_{t}$ is monitored as before. The same switch also reverses the polarity of the detector, and therefore the sign of the indication. The slightly modified equation for $\delta_{t}$ is eq 11 in appendix II.

A galvanometer may also be used as a detector but since the circuit resistance is relatively high a photoelectric amplifier is necessary for sufficient sensitivity. The scale must be linear over the portion to be used and a scale calibration is also necessary to relate the readings in divisions or millimeters to a voltage change. The calibration can be made quite easily however by moving switch $\mathrm{S}_{1}$ from READ to CAL with $\mathrm{k}_{2}$ closed and observing the resulting deflection change. This increases the resistance of the $1000-\Omega$ divider by $0.5 \Omega$ and changes the divider current by 0.05 percent. The
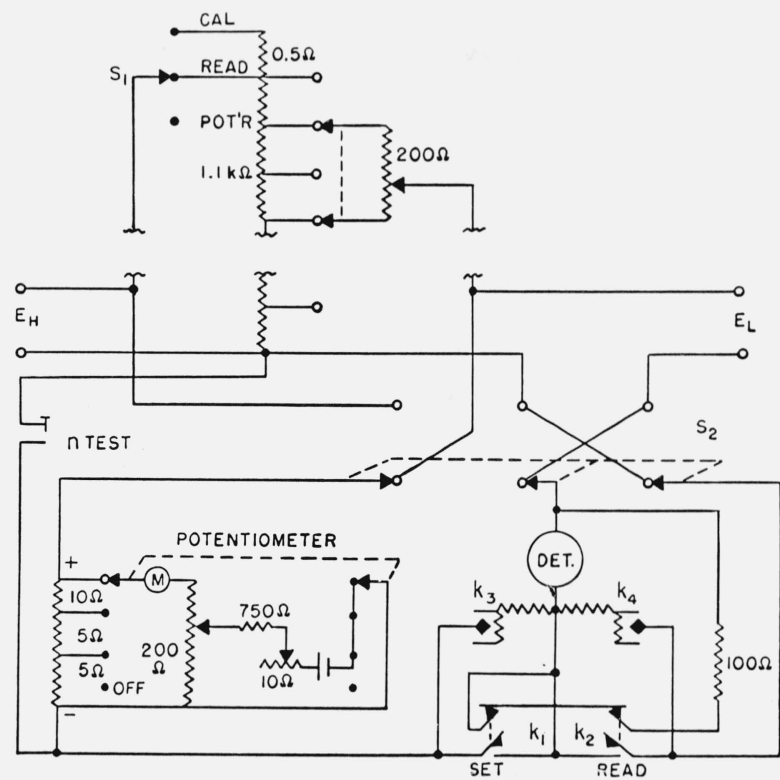

FigURE 8. New TE comparator.

\footnotetext{
${ }^{6} \delta_{t}-\delta_{s}$ is conveniently in parts-per-million if $E_{s}$ is in millivolts and $N_{d}-N_{a}$ is in nanovolts.
} 


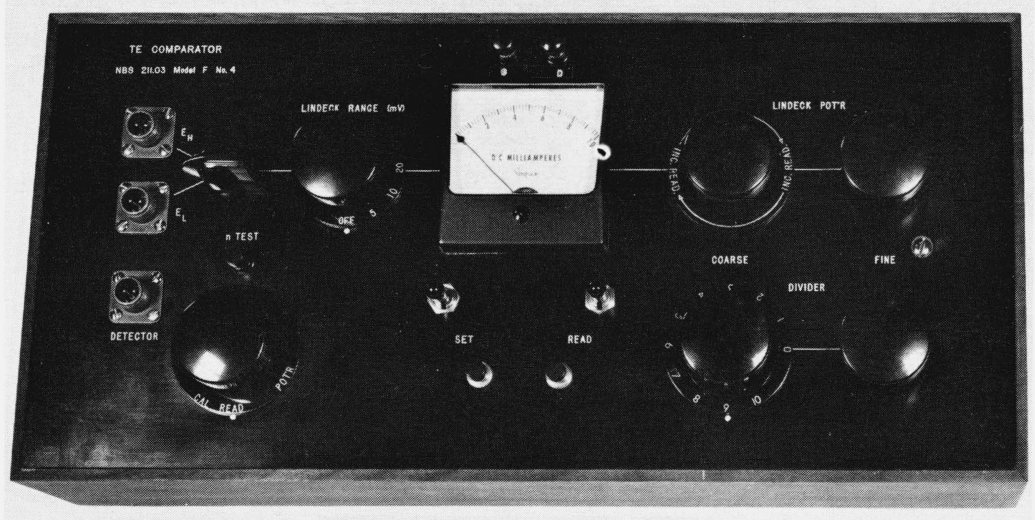

FIGURE 9. Photograph of TE comparator.

voltage applied to the galvanometer circuit is changed by the same amount and the deflection change $D_{1}$ is used in eq 10 and 12 in appendix 2 to determine $\delta_{t}$. A measurement of $E_{s}$ is made only to find the corresponding value of $n_{s}$ from a plot as before.

\section{8. $n$ Tests}

Measurements of $n$ are conveniently made with the comparator. The thermoelement to be tested is connected to the $\mathrm{E}_{\mathrm{L}}$ input and the $\mathrm{E}_{\mathrm{H}}$ input is unused. $\mathrm{A}$ key labeled " $n$ TEST" (fig. 6) is locked down and switch $S_{2}$ is moved to $E_{H}$ connecting the potentiometer voltage across the divider. The divider is set arbitrarily but preferably near full range and the potentiometer is adjusted to null the detector. The input voltage is then changed by a small measured amount $\Delta V / V$, and the resulting change in TE output $(\Delta E)$ is measured by observing the change in indication of the detector (nanovolts or microvolts). ${ }^{7}$ Switch $\mathrm{S}_{2}$ is then moved to $\mathrm{E}_{\mathrm{L}}$ and a measurement of $\mathrm{TE}$ output $(E)$ is made with the potentiometer. The values for each factor of the equation given above $(n=V \Delta E$ / $E \Delta V$ ) are then known and $n$ is calculated from this equation.

If a galvanometer is used as the detector a measurement of $D_{1}$ is made as described above, and the deflection change resulting from the measured change in input voltage $(\Delta V)$ is designated $D_{2}$. Then $n=0.05$ $D_{2} / q D_{1}$, where $q$ is the percentage change in input voltage $(100 \Delta V / V)$.

Determinations of $n$ need be accurate only to a few percent, and, since they are quite stable, retesting is not usually necessary.

\section{AC Voltage Measurements}

As suggested earlier, the comparator may be used with one TVC to measure an a-c voltage such as the

\footnotetext{
${ }^{7}$ A small change in the input to a TVC can be measured with a volt box and potentiometer or by a setting with a calibrated d-c voltage supply. It is also convenient to use a resistor with a shorting switch in series with a TVC to introduce a small current change $(\Delta I)$ in the thermoelement heater (i.e., $20 \Omega$ with a $40-\mathrm{k} \Omega, 200$-V TVC will give $100 \Delta I / I=$ 0.05 percent which is equivalent to $100 \Delta V / V)$.
}

input to a digital voltmeter or the output of a calibrated a-c voltage supply. Switch $S_{1}$ has a third position marked "POT'R" which disconnects the divider from the $E_{H}$ input. If a TVC output is connected to $E_{H}$, and switch $S_{2}$ is moved to that input, the potentiometer and detector can be used to measure the TVC output and changes in it. The circuit is as figure 5 without the test TVC. The d-c voltage is accurately measured and nominally equal to the a-c voltage.

It is suggested that $d-c$ voltage be applied to the TVC first and a detector reading taken. Then, at nearly equal time intervals, a second reading is taken with a-c voltage and a third with reversed $d-c$ voltage. The difference between the average of the readings with a d-c voltage $\left(E_{d}\right)$ and the one with a-c voltage $\left(E_{a}\right)$ is related to the input voltage difference very much as before.

$$
V_{\mathrm{ac}}=V_{\mathrm{dc}}\left(1+\frac{E_{a}-E_{d}}{n E}+\delta_{s}\right)
$$

With a nanovoltmeter the emfs are read directly, but if the detector is a galvanometer a scale sensitivity factor must be determined.

\section{Design Details}

The case of the TE comparator has thermal insulation and electrostatic shielding, and the comparator is carefully built to minimize thermal emfs and contact resistances. The switch decks of the Kelvin-Varley divider and $S_{1}$ and $S_{2}$ have enclosed silver contacts and the keys $k_{1}$ and $k_{2}$ are of a low-thermal type. The back contacts on these keys connect a $100-\Omega$ shunt across the detector to reduce sensitivity and noise until one key or the other is depressed. The fine control for the divider is a ten-turn helical resistor with a special lowthermal sliding contact. The resolution of the uncalibrated divider is not quite sufficient for setting an exact null on the detector, but setting within a few divisions is adequate in the ordinary use of the instrument. 


\section{Conclusion}

The use of one resistor unit for two TVC voltage ranges has reduced by about half the time required, over previous TVC sets, to make a complete intercomparison test. Changes in any member of the set are readily detected since frequent intercomparison tests are more feasible.

The TE comparator combines the stabilizing feature of other comparators with much of the simplicity of the single Lindeck potentiometer or balancing circuit. It is relatively inexpensive to build and calculations are simplified and direct, especially where the detector is a nanovoltmeter. Repeated tests have shown that the imprecision is less than $2 \mathrm{ppm}$ and ac-dc transfer accuracies, with the TVC set, are $10 \mathrm{ppm}$ at audio frequencies and $20 \mathrm{ppm}$ up to $50 \mathrm{kHz}$.

This work was supported in part by the Army Metrology and Calibration Center, Redstone, Alabama. Their encouragement and support are gratefully acknowledged. The author also acknowledges the help of C. B. Childers and A. G. Perrey who made many of the exacting measurements described here.

\section{References}

[1] Hermach, F. L. and Williams, E. S., Thermal converters for audiofrequency voltage measurements of high accuracy, IEEE Transactions on Instrumentation and Measurement, IM-15, No. 4, 260-268, (Dec. 1966).

[2] Hermach, F. L. and Williams, E. S., Thermal voltage converters for accurate voltage measurements to 30 megacycles per second, Trans. AIEE (Communication and Electronics), 79, Pt. I, 200-206, (July 1960).

[3] Turgel, Raymond S., A comparator for thermal ac-de transfer standards, ISA Transactions, 6, No. 4, 286-292, (1967).

\section{Appendix I}

The temperature coefficient of emf, $\beta$, of the average $\mathrm{TE}$ is about -0.2 percent $/{ }^{\circ} \mathrm{C}$, with constant input current. Thus a corresponding decrease in the resistance, $R=R_{c}+R_{t}+R_{s}$ (see fig. 7) is required to maintain a constant voltage across the resistor $R_{s}$. For a 1 degree increase in temperature, the

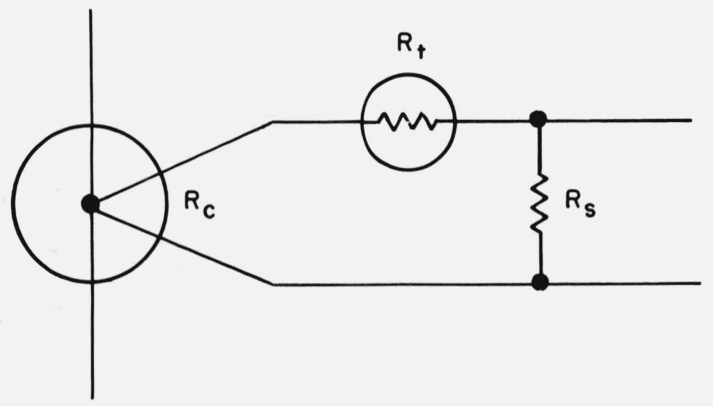

FigURE 7. Thermal compensation for TE.

$R_{c}$ TE output resistance (about $10 \Omega$ ).

$R_{t}$ Thermistor resistance (about $10 \Omega$ ).

$R_{s}$ Series resistor to complete compensation circuit. $\left(R_{c}\right.$ and $R_{s}$ have negligible temperature coefficients.) change in thermistor resistance, $\Delta R_{t}=\alpha R_{t} / 100$ where $\alpha$ is the temperature coefficient of the thermistor in percent $/{ }^{\circ} \mathrm{C}$-typically about -4 percent $/{ }^{\circ} \mathrm{C}$. Therefore, for thermal compensation,

$$
\begin{gathered}
\beta=100 \Delta R_{t} / R=\alpha R_{t} / R \\
\quad \text { and } R=\alpha R_{t} / \beta
\end{gathered}
$$

With the typical values listed we find $R=200 \Omega$, and, subtracting $R_{c}$ and $R_{t}$, the value for $R_{s}$ is $180 \Omega$.

\section{Appendix II}

\section{Development of Equations"}

The ac-dc difference of a TVC is defined as

$$
\delta=\frac{V_{a}-V_{d}}{V_{d}}
$$

where $V_{a}$ is the a-c voltage and $V_{d}$ the average of the two directions of dc-voltage required to produce the same output emf. In the circuit of figure 6 the a-c and d-c voltages are adjusted to give the same emf $E_{t}$, of the TVC under test, as indicated by a null on the detector $N$ with $\mathrm{k}_{1}$ closed. The same voltages are applied to the standard TVC. Then,

$$
V_{a}=V_{d}\left(1+\delta_{t}\right)=V_{d}^{\prime}\left(1+\delta_{s}\right)
$$

where $V_{d}^{\prime}$ is the d-c voltage required to produce the same output emf of the standard as $V_{a}$, and the subscripts, $t$ and $s$, refer to the test and standard instruments respectively. If $V_{d}^{\prime}-V_{d}<<1$, then, closely enough

$$
\delta_{t}-\delta_{s}=\frac{V_{d}^{\prime}-V_{d}}{V_{d}}
$$

From the definition of $n$ given in the paper

$$
\delta_{t}-\delta_{s}=\frac{E_{s a}-E_{s d}}{n_{s} E_{s d}}
$$

With the polarities as shown in figure 6 ,

$$
N=m E_{t}-E_{s}
$$

where $N$ is the detector voltage with $\mathrm{k}_{2}$ closed and $\mathrm{k}_{1}$ open, and $m$ is the divider ratio (with the detector resistance $R_{d}>>R_{1}$ ).

Thus.

$$
\delta_{t}=\delta_{s}+\frac{N_{d}-N_{a}}{n_{s} E_{s d}}
$$

where the subscript $a$ and $d$ have the same meaning as before.

${ }^{8}$ These equations were developed by F. L. Hermach. 
If a galvanometer is used as the detector, the current through it with $\mathrm{k}_{2}$ closed is, by Thevenin's Theorem,

$$
I_{g b}=\frac{m E_{t}-E_{s}}{R_{e}}
$$

where $R_{e}$ is the resistance of the galvanometer circuit with $E_{t}$ and $E_{s}=0$. With $E_{t}$ and $E_{s}$ held constant and $p R_{1}$ inserted by means of $S_{1}$,

$$
I_{g c}=\frac{m E_{t} /(1+p)-E_{s}}{R_{e}^{\prime}}
$$

where $R_{e}^{\prime}$ is the resistance of the galvanometer circuit.

Since $m E_{t}-E_{s}<<E_{s}$ and $p<<1$, we have to a sufficient degree of approximation,

$$
I_{g b}-I_{g c}=\frac{E_{s} p}{R_{e}}=\frac{\left(D_{b}-D_{c}\right)}{S}=\frac{D_{1}}{S}
$$

where $D_{b}$ and $D_{c}$ are the resulting galvanometer deflections and $S$ is the galvanometer current sensitivity.

In the ac-dc test, with $m E_{t}$ constant,

$$
I_{g a}-I_{g d}=\frac{E_{s d}-E_{s a}}{R_{e}}=\frac{D_{a}-D_{d}}{S}
$$

Thus, from (3), (8) and (9),

$$
\delta_{t}=\delta_{s}+\frac{p\left(D_{d}-D_{a}\right)}{n_{s} D_{1}}
$$

The test and standard TVCs may be interchanged if $E_{t}<E_{s}$. If $E_{t}$ is applied to the $\mathrm{E}_{\mathrm{L}}$ input of figure 8 and held constant, with the detector and potentiometer connected as shown in the figure, a similar analysis leads to the following equations:

$$
\delta_{t}=\delta_{s}+\frac{N_{d}-N_{a}}{n_{s} E_{t}}
$$

and

$$
\delta_{t}=\delta_{s}+\frac{p\left(D_{d}-D_{a}\right)}{n_{s} D_{1}}
$$

The characteristic $n$ is determined from

$$
n=\frac{\Delta E / E}{\Delta V / V}
$$

by applying known changes in input voltage and observing the changes in output emf with a high resistance voltmeter, as described in the text. If a galvanometer is used as the detector instead of the voltmeter its sensitivity is determined by inserting $p R_{1}$ as described. From equations similar to (8) and (9)

$$
\frac{\Delta E_{s}}{E_{s}}=\frac{p \Delta D}{D_{1}}
$$

If the thermocouple resistance of the test TVC, $R_{t c}$, is significant, $p$ in equation (7) should be replaced by $p^{\prime}$, the fraction of $R_{1}+R_{t c}$ inserted by $S_{1}$. Similarly if the potentiometer resistance $R_{p}$ is significant, $p$ in equation (14) should be replaced by $p^{\prime \prime}$, the fraction of $R_{1}+R_{p}$ inserted by $\mathrm{S}_{1}$.

(Paper 75C3\&4-321) 